Research in Microbiology

November 2015, Volume 166, Issue 9, Pages 665-667

http://dx.doi.org/10.1016/i.resmic.2015.08.003

http://archimer.ifremer.fr/doc/00277/38850/

(C) 2015 Institut Pasteur. Published by Elsevier Masson SAS. All rights

reserved.

\title{
Deep sea, the last great unexplored Earth frontier harboring the largest unknown and untapped remote microbial diversity on our planet
}

\author{
Jebbar Mohamed ${ }^{1,2,3,{ }^{*}}$ \\ ${ }^{1}$ Université de Bretagne Occidentale, UMR 6197-Laboratoire de Microbiologie des Environnements \\ Extrêmes (LM2E), Institut Universitaire Européen de la Mer (IUEM), 4 rue Dumont d'Urville, Technopole \\ Brest-Iroise, 29280 Plouzané, France \\ ${ }^{2}$ CNRS, UMR 6197-Laboratoire de Microbiologie des Environnements Extrêmes (LM2E), Institut \\ Universitaire Européen de la Mer (IUEM), 4 rue Dumont d'Urville, Technopole Brest-Iroise, 29280 \\ Plouzané, France \\ ${ }^{3}$ Ifremer, UMR 6197-Laboratoire de Microbiologie des Environnements Extrêmes (LM2E), Technopôle \\ Brest-Iroise, BP70, 29280 Plouzané, France \\ * Corresponding author: Mohamed Jebbar, Tel.: +33 298498 817; \\ email address : mohamed.jebbar@univ-brest.fr
}




\section{EDITORIAL}

\section{Deep sea, the last great unexplored Earth frontier harboring the largest unknown and untapped remote microbial diversity on our planet}

The deep sea microbiology workshop series aimed to gather international experts in the field, and give them the opportunity to present up to date scientific research, and to discuss future cooperative works, in a friendly atmosphere. The idea of a series of workshops dedicated to deep sea microbiology was conceived first during the Extremophiles Conference held in Brest in September 2006. Prof. Dr. Xiao Xiang (University of Shanghai, China) has organized the first edition in Xiamen (China) in November 2008, where he was settled at that time. This meeting was very successful and a second edition has been organized by Prof Daniel Prieur and Prof Mohamed Jebbar in 2010 in Brest, France. Again, the $3^{\text {rd }}$ edition was organized by Prof Xiao Xiang in Shanghai in October 2012 and in September 2014 Prof Mohamed Jebbar has organized the $4^{\text {th }}$ edition in Brest.

It is noteworthy to notice that the beginning of deep-sea microbiology is correlated with the Challenger Expedition (1873-1876) that is commonly credited as the historical beginning of deep-sea biology. The finding of live specimens at great depths obliterated the azoic-zone theory that had been suggested in the 1840s by Edward Forbes, a leading British oceanographer. Based on observations of the diminishing quantities of bottom fauna with increasing depth, it had been believed that no life existed below approximately $600 \mathrm{~m}$. The death of this theory was accompanied by the dispatch of Bathybius, because this foremost and universal microorganism had promised, however briefly, a splendid start of deep-sea microbiology [1].

In the seas and oceans, light and photosynthetic productions occur in the upper 300-m layers, temperature decreases with depth until an almost constant $3^{\circ} \mathrm{C}\left( \pm 1^{\circ}\right)$ is reached below the thermocline $(30-100 \mathrm{~m})$. To encompass a zone typified for its remoteness from the productive surface waters and attendant seasonal and topographically derived fluctuations in physical properties, the deep sea is conveniently defined as waters of $1,000 \mathrm{~m}$ and below [1]. It underlies $88 \%$ of the global area covered by seawater and includes $75 \%$ of the oceans' total volume, and it could represent up to $70 \%$ of all cells on Earth, as well as $50 \%$ of the primary production of biomass. The average depth is $3,800 \mathrm{~m}$, and the maximum depth in the trenches can reach $11,000 \mathrm{~m}$, but the volume of seawater below the "abyssal plain" (about $6,000 \mathrm{~m}$ ) is only $0.1 \%$ of the total. Most of these biotopes are oligotrophic in nature, and characterized by high hydrostatic pressures (HHP). Although the deep sea represents the largest ecosystem on Earth, however, it is still poorly characterized in terms of diversity or adaptation to HHP. The deep sea is principally an oligotrophic, cold, dark, and high-pressure environment, and these properties were not too long ago considered its only attributes. Now we know that deep-sea brines, seeps, and especially hydrothermal vents also contribute significantly to the variety of deep-sea extreme environments. Less life can survive in the deep sea than in other parts of the ocean but there are at least two extreme environments in the deep sea where life is more abundant. These are cold seeps and hydrothermal vents. In these environments, food chains do not begin with plants or algae that make food from sunlight but life is based on microbial (Archaea and Bacteria) chemosynthesis to produce biomass from single carbon molecules.

These deep-sea environments are governed by a set of physico-chemical constraints and various environmental properties that make them all different. Nevertheless, microbial communities and 
animals thriving in these ecosystems share many similarities suggesting that these ecosystems might be connected. The extent and importance of deep-sea environments only begin to be estimated, while the deep geographical limits under the sub seafloor are not yet established

During the $4^{\text {th }}$ edition of the deep sea microbiology workshop, many interesting talks and posters were presented and below I summarized the main results presented and discussed by the attendees, Dr Anna louise Reysenbach (Portland State University, Portland OR97201, USA) said that geochemistry alone does not influence the patterns of microbial diversity at vents, however the geochemical forces affecting hydrothermal vent microbial communities, at the genomic and genus level, vent microbes exhibit a biogeography. Dr Stephan Sievert (Woods Hole Oceanographic Institution, Woods Hole, MA 02543, USA) added that the high taxonomic diversity observed at deepsea vents is not necessarily reflected in functional diversity, such that different taxa can perform similar functions using homologous pathways, but being optimally adapted to slightly different environmental conditions. Such a strategy might impart robustness to the overall performance of the community and its response to the dynamic vent environment that is characterized by steep thermal and redox gradients, as well as frequent disturbances. Dr ken Takai (Japan Agency for Marine-Earth Science \& Technology) described Shinkaia crosnieri a hydrothermal vent crab which uses its maxillipeds to ingest its epibiotic microbial community composed of epsilon-proteobacterial, gammaproteobacterial thiotrophs, and occasionally of gamma-proteobacterial methanotrophs, and $S$. crosnieri assimilates these epibiotic Bacteria in the intestine as nutrition source. Dr Karine Alain (CNRS-UBO-Ifremer, IUEM, Plouzané, France) introduced another deep sea ecosystem, the subseafloor biosphere and the drilled site of the Canterbury basin where diverse microorganisms persist down to 1922 meters below the seafloor (mbsf) of the Canterbury Basin and extend the previously known depth limits of microbial evidence from 159 to 1740 mbsf for Eukarya and from 518 to 1922 mbsf for Bacteria. Dr. Michail M. Yakimov (Institute for Coastal Marine Environment, CNR, 98122 Messina, Italy), explained that dark primary production in bathypelagic interior of Mediterranean Sea is associated with different metabolic processes, including chemolithoautotrophy and heterotrophic assimilation of bicarbonate. In the absence of active thaumarchaeotal population, the last process may significantly contribute to de novo synthesis of organic carbon in deep-sea and thus, implies an additional important role of heterotrophic bacterial populations in global biogeochemical cycles running in ocean's interior. Dr Murat Eren (Marine Biological Laboratory, JBPC (L-326), 7 MBL Street, Woods Hole, MA 02543 USA), introduced Information theory-based methods for microbial community analysis e.g. Minimum Entropy Decomposition (MED) that provide new insights on community structure and dynamics.

Dr Bruno Franzetti (Institut de Biologie Structurale (UMR 5075 CNRS-CEA-UJF), Grenoble, France) presented the effects of high-pressure conditions on the activity, stability, substrate specificity and co factor requirement of enzymes from hyperthermophilic piezophilic microorganisms isolated at different depth. He said that high pressure imposes diverse constraints on the proteins depending on their 3D structures, oligomeric state and biochemical activities. Dr Chiaki Kato (Japan Agency for Marine-Earth Science and Technology, Yokosuka, Japan) confirmed also that proteins and enzymes from psychrophilic piezophilic microbes were unique for adaptation to high-pressure environment and some of them were much more stable and active under elevated pressure conditions.

During the $4^{\text {th }}$ edition of the Workshop on deep sea Microbiology 2014 held in Brest, the organizers have proposed to publish a special Issue of deep-sea microbiology research with selected papers 
presented or not at the conference that will be published as regular papers, not as conference proceedings papers, in the Research in Microbiology journal with the agreement of the Chief Editor and the editor coordinator of the journal. The aims of the manuscripts published in this special issue are summarized below.

Yoshia et al., identified a temperate bacteriophage (termed vB_PstS-1) from the psychrotolerant gammaproteobacterium Pseudomonas stutzeri 1-1-1b, which was isolated from hadopelagic water (depth of $7000 \mathrm{~m}$ ) of the Japan Trench in the Northwest Pacific Ocean [2]. The PstS-1 phage belongs to the family Siphoviridae, but its genomic sequence and organization are distinct from those of any other well-known Siphoviridae phage. The PstS-1 genome harbors three distinct sequence regions corresponding to spacers within a single clustered regularly interspaced short palindromic repeat (CRISPR) locus in the rhizosphere-associated diazotrophic $P$. stutzeri A1501 genome. The extension of these spacers to the soil environment and the presence of many homologs of both the hadal deepsea phage PstS-1 and terrestrial Pseudomonas phages suggest the early co-evolution of temperate phages and their host genus Pseudomonas prior to the divergence of their habitational and physiological adaptation [2].

Lijing et al., described the diversity and physiological characteristics of fermentative hydrogenproducing Caloranaerobacter strains from deep-sea hydrothermal vent fields [3]. This study highlights the complexity of hydrogen metabolism in Caloranaerobacter, reflecting adaptations to environmental conditions in hydrothermal vent systems. Collectively, the results suggested that Caloranaerobacter species might be ubiquitous and play a role in biological hydrogen generation in deep-sea hydrothermal vent fields [3].

Guan et al., evaluated the relative abundance of Bacteria and Archaea in oceanic deep hypersaline anoxic basins (DHABs) of Red Sea, by using quantitative PCR and conducted phylogenetic analyses of nearly full-length $16 \mathrm{~S}$ rRNA genes as well as functional marker genes encoding the alpha subunits of methyl-coenzyme $\mathrm{M}$ reductase $(m c r A)$ and dissimilatory sulfite reductase (dsrA) [4]. Bacteria predominated over Archaea in most locations, the majority of which were affiliated with Deltaproteobacteria, while Thaumarchaeota were the most prevalent Archaea in all sampled locations [4]. This study revealed unique microbial compositions, the presence of niche-specific groups, and collectively, a higher diversity of sulfate-reducing communities compared to methanogenic communities in all studied locations [4].

Burgaud et al, have investigated the deep-sea microbial community compositions and shown unexpected micro-eukaryotic communities, mainly dominated by fungi; this study investigated morphological and physiological responses of fungi to High hydrostatic pressure (HHP) using a collection of deep-sea yeasts as a model [5]. This study reported an unexpected taxonomic-based dichotomic response to pressure with piezosensitve ascomycetes and piezotolerant basidiomycetes, and distinct morphological switches triggered by pressure for certain strains [5]. Cario et al., explored the amino acid requirements of a hyperthermophilic piezophilic archaeon Thermococcus barophilus strain MP and they showed a major impact of HHP on amino acid metabolism, with increases from three amino acids required at atmospheric pressure to seventen at $40 \mathrm{MPa}$ [6]. Only alanine, glutamine, and proline, were not essential for growth at $40 \mathrm{MPa}$, in contrast, glutamate, cysteine and tyrosine, were essential for growth at atmospheric pressure [6]. Vannier et al., showed that the HHP response in the $T$. barophilus is characterized by a global change in the expression of genes involved 
in some metabolic pathways, rather than expression of a stress response [7]. However, a stress response is observed in the piezosensitive species Thermococcus kodakarensis [7].

The deep biosphere is the last frontier on Earth which is less explored and has not yet delivers all its secrets and much remains to be done to understand and characterize the diversity, the functioning, the adaptation, and the survival of microbial communities thriving, persisting and or dwelling in the various ecosystems of the deep biosphere. The deep sea Microbiology workshop series will continue and each edition will be held every two years to bring together all scientists working on and interested by deep sea microbiology, this constitutes a unique opportunity to share new discoveries and to discuss future prospects and collaborations at the international level.

\section{References}

[1] Jannasch HW, Taylor CD. Deep sea microbiology. Ann Rev Microbiol 1984;38:487-514

[2] Yoshida M, Yoshida-Takashima Y, Nunoura T, Takai K. Identification and genomic analysis of temperate Pseudomonas bacteriophage PstS-1 from the Japan trench at a depth of $7000 \mathrm{~m}$. Res Microbiol 2015; 166 : http://dx.doi.org/10.1016/j.resmic.2015.05.001

[3] Jiang L, Xu H, Zeng X, Wu X, Long M, Shao Z. Thermophilic hydrogen-producing bacteria inhabiting deep-sea hydrothermal environments represented by Caloranaerobacter. Res Microbiol 2015; 166; http://dx.doi.org/10.1016/j.resmic.2015.05.002

[4] Guan Y, Hikmawan T, Antunes A, Ngugi D, Stingl U. Diversity of methanogens and sulfate-reducing bacteria in the interfaces of five deep-sea anoxic brines of the Red Sea. Res Microbiol 2015; 166; http://dx.doi.org/10.1016/i.resmic.2015.07.002

[5] Burgaud G, Thi Minh Hu N, Arzur D, Coton M, Perrier-Cornet JM, Jebbar M, et al. Effects of hydrostatic pressure on yeasts isolated from deep-sea hydrothermal vents. Res Microbiol 2015; 166 : http://dx.doi.org/10.1016/i.resmic.2015.07.005

[6] Cario A, Lormières F, Xiao X, Oger P. High hydrostatic pressure increases amino acid requirements in the piezo-hyperthermophilic archaeon Thermococcus barophilus. Res Microbiol 2015; 166 : http://dx.doi.org/10.1016/j.resmic.2015.07.004

[7] Vannier P, Michoud G, Oger P, Marteinsson VT, Jebbar M. Genome expression of Thermococcus barophilus and Thermococcus kodakarensis in response to different hydrostatic pressure conditions. Research in Microbiology 2015; http://dx.doi.org/10.1016/i.resmic.2015.07.006

\section{Mohamed Jebbar ${ }^{1,2,3}$}

${ }^{1}$ Université de Bretagne Occidentale, UMR 6197-Laboratoire de Microbiologie des Environnements Extrêmes (LM2E), Institut Universitaire Européen de la Mer (IUEM), 4 rue Dumont d'Urville, Technopole Brest-Iroise, 29280 Plouzané, France

${ }^{2}$ CNRS, UMR 6197-Laboratoire de Microbiologie des Environnements Extrêmes (LM2E), Institut Universitaire Européen de la Mer (IUEM), 4 rue Dumont d'Urville, Technopole Brest-Iroise, 29280 Plouzané, France 
3 Ifremer, UMR 6197-Laboratoire de Microbiologie des Environnements Extrêmes (LM2E), Technopôle Brest-Iroise, BP70, 29280 Plouzané, France

Email : mohamed.jebbar@univ-brest.fr

Phone: +33298498 817 